\title{
BOTERO TRAS DE SÍ MISMO
}

\section{Juan Gustavo Cobo Borda}

\section{RESUMEN:}

En este perfil del Maestro Fernando Botero, el escritor y poeta Juan Gustavo Cobo Borda nos ofrece un recorrido por la vida del pintor vivo más importante del mundo y sin lugar a dudas, uno de los más destacados del siglo XX. La rigurosa búsqueda del pintor por encontrar su rumbo en las artes plásticas, un estilo definido y su expansión a la escultura aflora en una semblanza reveladora que muestra que Botero es quien es, no sólo por la inmensidad de su talento, sino por una inquebrantable búsqueda por superarse a sí mismo mediante una juiciosa y continua autocrítica.

\section{ABSTRACT:}

In this profile, the writer and poet Juan Gustavo Cobo Borda gives us a tour of the life of the largest living pain- ter in the world, and undoubtedly one of the most prominent of the twentieth century, the Master Fernando Botero.

Botero's rigorous search to find its course in the fine arts, a defined style and its expansion to the sculpture emerges in a revealing portrait showing that Botero is who he is, and not only because of the immensity of his talent but by a steadfast search that overcome himself through a careful and continuous self-criticism.

\section{PALABRAS CLAVE:}

Viajes, realista, monumental, virtuoso, reminiscencias.

\section{KEYWORDS:}

Travels, realist, monumental, virtuoso, reminiscences.
La vida, y la pintura de Fernando Botero, han estado marcadas por varios viajes decisivos. El primero de ellos es el que lo llevó de Medellín a Bogotá en 1951, luego de graduarse de bachiller. Expondría en la galería de Leo Matíz, singular fotógrafo nacido en Aracataca, como García Márquez, y quien en México había retratado a María Félix, Diego Rivera, Frida Khalo y había servido incluso de modelo para murales de David Alfaro Sequeiros. Allí expuso Botero en dos ocasiones, en 1951 y 1952, y entre una y otra muestra viajó a Tolú, Coveñas y San Bernardo del Viento en el Caribe colombiano.
Las influencias determinantes eran las de Picasso azul y rosa y del cubista de Las señoritas de Avigñon del cual toma incluso el célebre frutero. Pero el Gauguin que huyó a los trópicos se hará más visible en las alargadas siluetas de negros perfiladas entre palmeras, en un angular entierro o como En frente al mar, de1952, en el cuerpo del hombre que otros dos llevan a hombros, amarrado de manos y pies a dos largos palos. La pareja de niños y el hombre con bastón que los acompaña acentúan la irrealidad de este duelo, tan solitario y tan impregnado de la luminosa atmósfera caribe. 
Medio siglo más tarde, entrevistado por la revista Soho Botero recordará el momento inolvidable en que vio por primera vez las Meninas, de Velásquez, situada entonces en un salón más pequeño que el actual.
El estilo de Botero, a los 19 años, se hace evidente en los dibujos con que en 1951 iluminó el libro regalado por el poeta Fernando Charry Lara y titulado Nocturno y otros sueños (1949). Lector que glosa las imágenes del poeta, lector que ya desde su Medellín bohemio amaba a Neruda, García Lorca y sobre todo César Vallejo, aquí desnuda, en muy pocos trazos, cuerpos femeninos sobre la arena, dándoles a sus cabelleras flotantes y alargadas el impulso de una ensoñación romántica, de "mar inmenso sin nostalgia de costa", como diría el poeta. Y a las visiones de la ciudad, con sus hombros rígidos y enfundados en gabardinas, algo de ese mundo fantasmal de ángeles y sus maniquíes que caracterizó a Jean Cocteau y Giorgio de Chirico. Un toque deliberadamente poético, según las convenciones de la época.

Salía de sus montañas, acababa de conocer por fin el mar a los 18 años, ya no le bastaban las simples reproducciones y a los 7.000 pesos ganados en su segunda exposición donde Leo Matíz, en mayo de 1952, añadirá los 2.000 pesos del segundo premio en el IX Salón Nacional de Artistas colombianos con el ya mencionado En frente del mar. Suficiente para dar el gran salto, en el vapor italiano Usodimare y desembarcar en el puerto de Barcelona, España, donde podrá contemplar, al fin, pintura de verdad.

\section{RESEÑA DEAUTOR}

Juan Gustavo Cobo B. poeta y ensayista bogotano, fue director durante una década (1973-1984) de la Revista Eco, de Bogotá. Ha ocupado cargos diplomáticos en Buenos Aires y Madrid y fue embajador en Grecia. Miembro número de la Academia Colombiana de la lengua desde 1993, y correspondiente de la Academia española. Ha sido jurado tres veces del Premio Juan Rulfo, (Guadalajara, México); del Rómulo Gallegos, (Caracas); del Reina Sofía de poesía iberoamericana (Madrid) y del Neustad, Universidad de Oklahoma, estados Unidos.
Enseguida Madrid, donde el museo por excelencia, El Prado, le permitirá vivir en y de la pintura quizá de la manera más expedita: hará copia de los cuadros más famosos para vender a los turistas: Velásquez, Ticiano, Goya. Una lección impar que lo marcará para siempre y que dará enseñanzas más fructíferas que su breves semestres en la Real Academia de Bellas Artes de San Fernando donde un profesor que poco iba, Julio Moisés, le dio la única lección que recuerda. Aburrido de dibujar la consabida modelo, Botero esbozará el radiador detrás suyo. El maestro académico le advertirá entonces: "no hay que ser demasiado realista".

Medio siglo más tarde, entrevistado por la revista Soho Botero recordará el momento inolvidable en que vio por primera vez las Meninas, de Velásquez, situada entonces en un salón más pequeño que el actual. "Al entrar al cuarto uno sentía que estaba entrando al cuadro. Era como meterse en el mismo ambiente que estaba pintado, era como entrar a la intimidad de esas adolescentes que salen ahí".

De tal impacto surgirían en sus variaciones sobre la Maribarbola, sus recreaciones de los bufones de Velásquez. En lo referente a Goya bien podemos pensar que su presencia ha resurgido con fuerza, en los últimos años, con sus series dedicadas a la corrida y a la guerra, sin olvidar que en sus célebres retratos de la familia presidencial (1967) o la junta militar (1971) estuvo presente la Familia de Carlos IV, 1800, de Goya. Robert Hughes en su penetrante libro sobre Goya (2004) nos ha dicho al respecto:

La superficie, esa libre y empastada capa de pigmento que despide luz por todas partes, llena de vitalidad y sin ningún toque apa- 
gado, refleja el Goya más vigoroso. Lejos de cultivar la sátira, la obra viene a ser una apología entusiasta de la monarquía: no de su carácter divino, desde luego, pero sí de lo que en épocas posteriores se denominará su glamour, su capacidad para deslumbrar al pueblo y a sus súbditos. (pág. 261)

Y, claro está, a los jóvenes pintores, como lo refrendaría la visita de Botero, luego del Prado de Madrid al Louvre de París.

Otro alud de suscitaciones y desafíos, que van desde los grandes retratos de aparato de los Luises hechos por Rigaud hasta las telas más delicadas de Madame Vigne Lebrun, desde los jugadores de cartas de Cezanne hasta las mujeres en la tina de Bonnard, sin olvidar nunca a Monsier Ingres y a su apego a la tradición gracias a la probidad del dibujo. A todos los cuales rendirá tributo en sus cuadros, al hacer variaciones "Boterianas" de los mismos.

Pero quien abría los ojos pasmados ante estos milagros artísticos nunca dejaba de ser paisa. La revolución francesa ya la había visualizado en los libros que ojeaba su padre en Medellín, luego de sus largas correrías a caballo, y con el tiempo, en 1990, lograría que Luis XVI y María Antonieta visitaran a Medellín, en un sorprendente séptico, hoy donado al Museo de Antioquia. Se está apropiando, poco a poco, del mundo, y retrataría tanto a Madame Cezanne como al propio Paúl Cezanne (1994), dentro de su largo diálogo creativo, homenaje y profanación, con la pintura europea, del cual bien puede ser epitome de refinamiento, maestría y brillante luminosidad el retrato de Alof de Vignacourt (1608) pintado por Caravaggio, hoy en el Louvre, y recreado por Botero en 1974. La soberbia postura de este militar, la refulgente armadura y el paje con el casco, han recibido el toque Botero, y así su cara más ancha y feroz y sus piernas más rotundas y firmes lo llevan a dominar toda la atmósfera y a volver mucho más niño y mucho más frágil a su acompañante. Con estos relámpagos de luz estremecida se confirma entonces la etapa clave de este viaje de iniciación: Italia.

\section{EL MILAGRO ITALIANO}

En Florencia de 1953 a 1955, estudiará la técnica del fresco, asistirá a las conferencias libres de Roberto Longhi y recorrerá extasiado la propia Florencia, Piza, Siena, Bolonia y Venecia. Pero el encuentro decisivo se dará en Arezzo: los frescos de Piero Della Francesca. Quiso ser sólido y monumental como lo era el maestro, y asimilar sus características que Carlo Ginzburg en su libro Pesquisa sobre Piero (1984) ha descrito así:

"La impasibidad de las figuras, la solemnidad de la composición, la complejidad de la perspectiva...y y a siguiendo las huellas de los flamencos,... la representación de los efectos de luz" (p.30).

Pero también quiso que sus pinturas estuviesen revertidas de una hierática lejanía, plena a la vez de densidad y misterio como esa Reina de Saba y esas otras figuras del santoral católico. La nostalgia griega, la caída irremediable de Constantinopla, el renacer humanista y el cuerpo del hombre, flagelado o en combate, orando o en reposo, caído o resucitado con gloria, desvelarían a Botero, quien lo estudiaría en todas sus formas. A la vez esa impersonalidad, "cosa aparte de mí" haría que las figuras de Piero están "como en el vacío" y parezcan carecer de expresión. 
Un arte de gran calma donde prima más la masa que la línea y los rostros, en ocasiones profundos, parecen carecer de sentimientos, como señaló Kenneth Clark.
"La pintura tiene que partir de la pintura" afirmaba en una entrevista de 1968 con Cecilia Isaacs y pocos años más tarde su Madre Superiora de 1958, su Niña perdida en el jardín y su Monalisa a los 12 años, ambos de 1959, nos confrontan, mirennos de frente o sonrían al sesgo, revestidas ya de esa fría atemporalidad avasallante con que saturan la totalidad del lienzo, dignas herederas en el trópico informe de la austeridad geométrica del maestro de Borgo San Sepulcro. Un arte de gran calma donde prima más la masa que la línea y los rostros, en ocasiones profundos, parecen carecer de sentimientos, como señaló Kenneth Clark.

Lionello Ventura en su Piero Della Francesca (1954) había señalado cómo "la obra de Piero nace de la contemplación estática de un mundo donde la vida fluye con tanta intensidad que ella semeja pertenecer a la eternidad y donde vida y muerte parecen fundirse en una existencia superior". (p.7).

Pero naturalmente Piero Della Francesca no sería la única figura influyente y suscitadora de su periplo italiano. Mantegna (14311506) con sus frescos en el Palacio Ducal en Mantua referidos a la familia Gonzaga recibiría muy pronto un singular homenaje: la Camera degli Sposi, de 1958, le permitiría a Botero mediante seis figuras, cuatro de frente y dos de perfil a la izquierda, más un animal, combinar animales de dos frescos del artista, y brindarnos una compacta composición de bloques macizos e inquietantes. Esos ojos perturbadores en su fijeza, incluído el animal, esa variedad de sombreros tan altos como anchos, esas manos rechonchas y esas pinceladas visibles hacían de esos volúmenes una sorpresiva confabulación de rollizos enanos posando para una equívoca ceremonia. La mano que parece bendecir, desde lo alto, y la niña arrodillada a los pies de la figura central, con su manzana, combinan risueña familiaridad con grave lejanía y el explícito letrero que proclama "Homenaje a mantegna" sugiere admiración con irreverencia.

De este modo el humor explícito en esta deformación de un mundo ritualizado, en esta pequeña corte renacentista, no soslaya su preocupación fundamental por explorar, desde dentro, el orbe de la pintura. Un mundo que mantiene sus claves en sí mismo. Al obtener el primer premio en el XI Salón de Artistas Nacionales de 1958, luego de una ruidosa polémica, Walter Engel quien junto con Casimiro Eiger fueron los primeros críticos extranjeros residentes en Colombia que siguieron con interés y perspicacia la trayectoria de Botero, desde sus inicios, escribió:

Es uno de los cuadros más discutidos que se hayan exhibido jamás en Bogotá. Es una obra difícil y desconcertante al primer contacto. No hace concesiones. No se acerca al espectador, no le facilita su tarea receptiva, no trata de agradar. Se mantiene en una respetuosa distancia, en hierática inmovilidad, en una alejada, autónoma y arrogante existencia propia. (W. Engel, revista Plástica, Bogotá, No. 12, 1958).

Engel también habló de la reminiscencia de algunas de las figuras "consciente o inconscientemente de las estatuas de San Agustín. De la pétrea monumentalidad propia de esa estatuaria”.

Intrigante aproximación entre lo precolombino y lo renacentista. Entre la arrogancia cruel de esas piedras insomnes que vieron correr tanta sangre para alimentar la cíclica rotación del cosmos y esa refi- 
nada urdimbre de neoplatonismo, cortesía maquiavélica, mecenazgo artístico y feroces condotieros en guerras fratricidas que también tiñeron de sangre esos castillos ornados con tan sublimes pinturas, incluidas las estancias vaticanas de la Roma papal.

Mucho más aprendería Botero de este periplo italiano, y sin ser exhaustivos podemos mencionar los caballeros de Paolo Ucello con sus jinetes desnudos sobre playas desiertas o alguna soberbia cabeza de Masaccio recreada en tinta por el antioqueño, como ilustrativos ejemplos.

En todo caso estás palabras de Marta Traba, en 1957, en la revista Prisma son una buena síntesis de los cambios que experimentó su estilo al contacto con Italia y su pintura.

La obra de Botero se dedica a organizar, a limitar las formas, a encerrarlas en la geometría, a desdecir, en una palabra, toda su anterior despreocupación, su ligereza y su lirismo. Después de ser drama y pieza musical, seconvierte en meditación. El peso de los colores se calcula y se extiende en grandes zonas equilibradas. Caballos uccellianos, con sus grandes grupas redondas, intervienen en el paisaje de colinas simétricas. La figura queda esclavizada a esta entusiasta adhesión a la dignidad antigua. Pesadas las masas geométricas del paisaje se compaginan mesuradamente, tratando de revivir, en el ámbito moderno, la concepción renacentista.

La vanguardia, en su vertiente tachista, que tanto lo había desilusionado en París, se había esfumado. El inagotable orbe de pintura italiana en los siglos XIII y XIV lo acompañarían para siempre y serían su referencia ineludible. Su hermoso paradigma.

\section{LA REVELACIÓN MEXICANA}

En 1945 José Clemente Orozco publicó su Autobiografía. Allí recordaba la vehemencia con que su colega, el doctor Ati, le hablaba de: "Las grandes pinturas murales". Los inmensos frescos renacentistas, algo tan increíble y tan misterioso como las pirámides faraónicas, y cuya técnica se había perdido por cuatrocientos años". (p.20).

Repudiaba luego Orozco el criterio académico que consideraba que sólo era factible copiar a imitar servilmente a los antiguos: "el dibujo florentino con el color veneciano". El propio Botero ha reconocido también otro influjo que se corrobora en México:

Lo que emocionó mucho en el estudio de Gómez Jaramillo fue una figura de arte popular. Esa figura influyó en mi trabajo definitivamente. Yo le he dado mucha importancia al arte popular como elemento de información; el arte popular me ha nutrido muchísimo. (p.283).

Y México, por cierto, es una tierra privilegiada en tal sentido. Allí pudo también Botero confrontar, de forma directa, su admiración por la pintura de Orozco tan perceptible en sus primeros cuadros, como la Mujer llorando, de 1949, con su tenso y desolado nudo en azules y grises y ya la rotundidad pétrea de esa mano superior que oculta el rostro y en $\mathrm{Sino}_{2}$ proyecta para mural de 1950, donde la dramática progresión de las siluetas trae el remoto eco de los perfiles colectivos en el trasfondo de los célebres muralistas contemplados entonces sólo en pálidas reproducciones.

Arte precolombino (las colosales cabezas olmecas), arte popular, al cual bien puede adscribirse la obra gráfica de José 
Guadalupe Posada y sus calaveras, recurrentemente también pintadas por Botero, a lo largo de toda su trayectoria: esqueletos de pie o sentados con un ramo de flores, que siempre nos desasosiegan, como en sus aparición fantasmal en una tela de Juan Soriano y el color, tan local como poético, que distingue a un virtuoso del mismo como Rufino Tamayo y bien podrían ser algunas de las estimulantes motivaciones halladas en su estadía mexicana.

Pero lo fundamental es lo que Botero mismo hacía en su pintura, la profundización en su búsqueda, que siempre recuerda el momento epifánico, en México cuando una mandolina creció, de modo desmesurado delante de sus ojos. Al trazar un pequeño agujero en el centro de su sólida figura, el instrumento musical se convirtió en un colosal bloque de mármol tallado por su austero pincel. Si el arte siempre ha sido deformación, como repite Botero, ahora lo había experimentado por sí mismo: había encontrado la llave para acceder a su mundo. Ya Botero es capaz de pintar con ira y como lo recuerda Alvaro Mutis, compañero suyo en esta temporada mexicana, esta era la ira fría e impersonal de los grandes creadores.

"El otro Botero es un monstruo de endemoniada lucidez, que registra, con el ojo implacable de un felino acecho, la cotidiana y sandia existencia de sus semejantes". 